\title{
Os Odontoideum, fijación transarticular C1-C2
}

\author{
Os Odontoideum, C1-C2 transarticular fixation \\ Christian Gerardo Colín González, ${ }^{*}$ Esteban Reyes Velasco ${ }^{\ddagger}$
}

Citar como: Colín GCG, Reyes VE. Os Odontoideum, fijación transarticular C1-C2. Acta Med. 2020; 18 (4): 427-428. https://dx.doi.org/10.35366/97274

Masculino de 58 años quien acude por referir parestesias de las cuatro extremidades, cervicalgia, paresia progresiva principalmente de miembros torácicos en los últimos seis meses. La exploración física mostró: extremidades con miembro torácico izquierdo con fuerza muscular para miotomos C5 (5/5); C6, C7, C8 y T1 (3/5), miembro torácico derecho 4/5 para todos los miotomos, hiperreflexia bilateral, Hoffman y Trommer positivos; miembros inferiores con fuerza y sensibilidad conservada, reflejos osteotendinosos con hiperreflexia y Babinski positivo, sensibilidad con parestesia generalizada, Ilenado capilar normal. Conserva control de esfínteres. Se solicitan estudios de imagen que mostraron: inestabilidad C1-C2 radiográfica (Figura 1A) y tomográficamente (Figura 1B), con distancia arco anterior del atlas a odontoides de $6 \mathrm{~mm}$ y distancia arco posterior del atlas a odontoides de $10 \mathrm{~mm}$ (Figura 1C); la resonancia magnética confirmó compresión medular a nivel del atlas
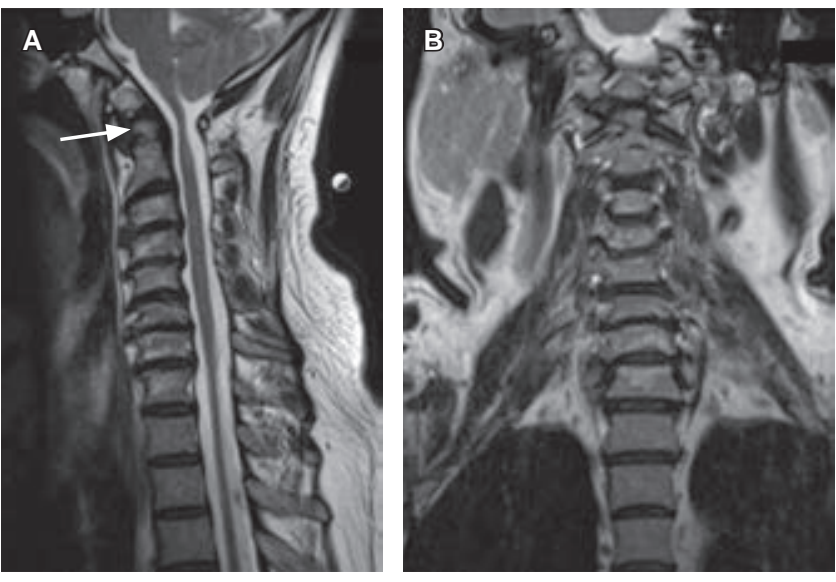

Figura 2: Imágenes de resonancia magnética en cortes sagital (A) y coronal (B), en las cuales se observa adelgazamiento medular importante a nivel del atlas.

Figura 1:

A) Radiografía lateral de columna cervical. B) Tomografía computarizada en corte sagital de columna cervical que muestra Os Odontoideum. C) Tomografía computarizada en corte axial que muestra en las dos últimas inestabilidad C1-C2 con distancia anterior de arco del atlas a odontoides de $6 \mathrm{~mm}$ y distancia arco posterior del atlas a odontoides de $10 \mathrm{~mm}$.
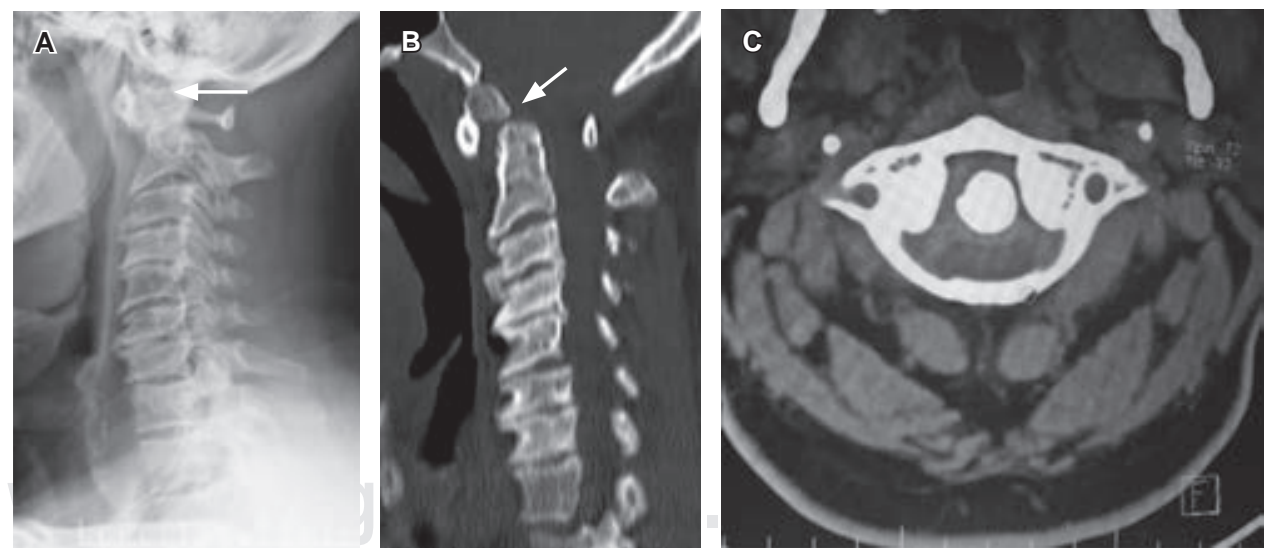

\footnotetext{
* Ortopedista.

₹ Neurocirujano.
}

División de Cirugía del Hospital Ángeles León. León, Guanajuato, México. www.medigraphic.com/actamedica
Correspondencia:

Christian Gerardo Colín González

Correo electrónico: drchristiancolin@gmail.com

Aceptado: 09-09-2019.

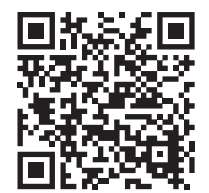



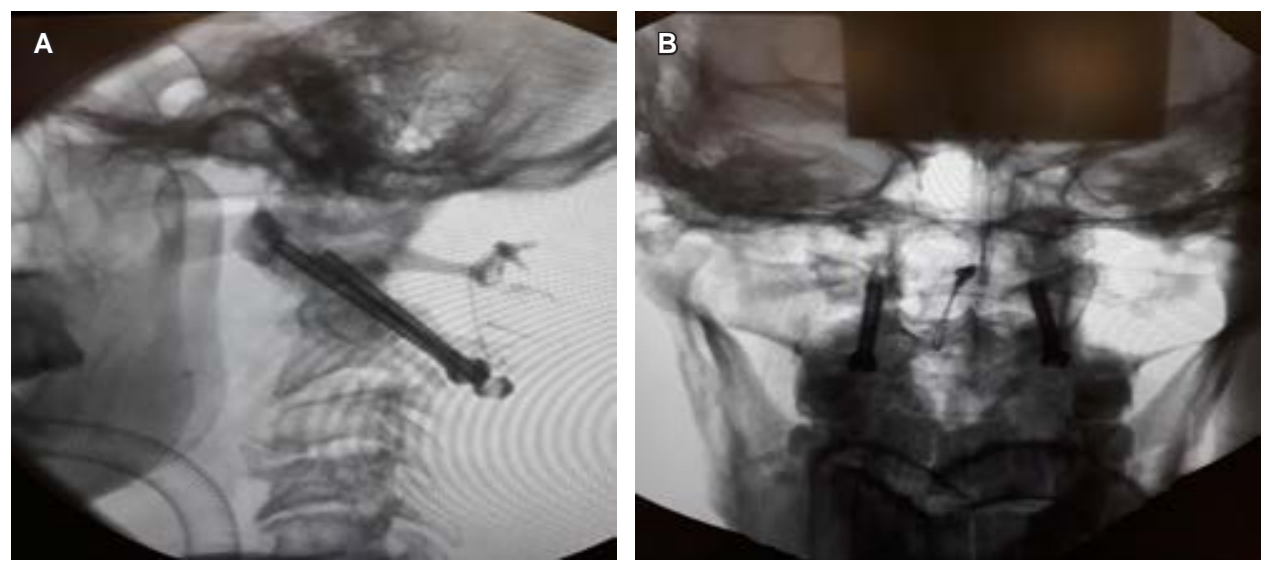

Figura 3:

Radiografía lateral (A) y anteroposterior (B) de columna cervical efectuada con fluoroscopio en el postoperatorio de artrodesis C1-C2 a $360^{\circ}$ con técnica de Magerl-Gallie modificada (colocación de dos tornillos transarticulares, alambrado sublaminar y aloinjerto).

(Figura 2A y B), el estudio de electromiografía y velocidad de conducción nerviosa compromiso confirmó compromiso neurógeno crónico de grado moderado; los potenciales evocados somatosensoriales mostraron miembro superior izquierdo con retardo de las latencias cervicotalámicas; miembros inferiores con retardo en el segmento periférico hasta el cono medular. Se efectuó: artrodesis C1-C2 a $360^{\circ}$ con técnica de Magerl-Gallie modificada (colocación de dos tornillos transarticulares, alambrado sublaminar y aloinjerto. A los seis meses de seguimiento el paciente se encuentra asintomático.

El Os Odontoideum es un defecto del cierre de los núcleos de osificación de la apófisis odontoides del axis. ${ }^{1,2}$ Se clasifica en sintomático y asintomático. En pacientes sintomáticos las principales manifestaciones clínicas son cervicalgia, cuadriparesia progresiva y accidentes vasculares. ${ }^{3} \mathrm{La}$ estabilización del segmento C1-C2 se ha modificado a través del tiempo, utilizando técnicas de fijación sublaminar, transarticular o su combinación; actualmente la técnica de
Harms (colocación de dos tornillos transarticulares C1-C2 y dos tornillos a las masas laterales de $\mathrm{C} 1$ ) ha demostrado biomecánicamente mayor fortaleza; sin embargo, presenta un riesgo muy elevado de lesión de estructuras nerviosas y vasculares, motivo por lo cual la mayoría de los autores continúan utilizando la técnica de Magerl modificada como método de tratamiento estándar (Figura 3).1,3,4

\section{REFERENCIAS}

1. Arvin B, Fournier-Gosselin MP, Fehlings MG. Os Odontoideum: etiology and surgical management. Neurosurgery. 2010; 66: 22-31.

2. Grob D. Atornillado transarticular C1/2 (técnica de Magerl). Rev Esp Cir Ortop Trauma. 2008; 52: 243-249.

3. Wu Z, Xu J, Wang Z, Xia H, Zhang Q, Yang MX et al. Transoral approach for revision surgery of os odontoideum with atlantoaxial dislocation. Orthopedics. 2014; 37: e851-e855.

4. Lee SH. Kim ES, Sung JK, Park YM, Eoh W. Clinical and radiological comparison of treatment of atlantoaxial instability by posterior $\mathrm{C} 1$ C2 transarticular screw fixation or C1 lateral mass-C2 pedicle screw fixation. J Clini Neurosci. 2010; 17: 886-892. 